\title{
Optimizing Online Learning Experiences and Outcomes for Hearing-Impaired Art and Design Students
}

\author{
Sama'a Al Hashimi \\ University of Bahrain, Sakheer - Kingdom of Bahrain \\ http://orcid.org/0000-0003-4355-8699 \\ Dalal Alsindi \\ University of Bahrain, Sakheer - Kingdom of Bahrain \\ http://orcid.org/0000-0001-9404-0123
}

\begin{abstract}
As many universities transitioned to online learning during the COVID-19 pandemic, the distance learning environment presented various accessibility challenges for deaf and hard-of-hearing students (DHH). In art and design higher education programs, the transition from face-to-face learning to virtual learning is difficult for students in general, and even more difficult for students with hearing loss. Art and design educators have explored approaches to effectively compensate for these challenges and optimize the distance learning experiences for $\mathrm{DHH}$ students. This paper aims to investigate these challenges and attempts to explore the international best practices in distance education for deaf learners. Action research is used as a methodology to guide the professional development of art and design educators on ways to refine and hone their online teaching approaches. Ten DHH students (5 Males and 5 females) participated in the action research for the needs of this study. Their challenges, experiences, preferences, needs and artworks were analysed in an attempt to optimize their online learning outcomes and provide recommendations that will lead to the implementation of effective teaching strategies and the design of appropriate e-learning environments for hearing-impaired art and design students. The preliminary findings of the study revealed that the main challenges $\mathrm{DHH}$ students and their instructors faced were communication barriers and misinterpretation of tasks, which led to difficulties in fulfilling the course intended outcomes. The recommendations formulated on the basis of the findings are to adapt the intended learning outcomes and teaching approaches to optimize the learning experiences of the DHH students.
\end{abstract}

Keywords: hearing-impaired; education; art; design; distance education 


\section{Introduction}

When the COVID-19 pandemic started, many industries and fields simply stopped functioning, while other fields flourished. Different sectors were forced to find solutions to the problems encountered caused by the pandemic. The effect of virtual education on students of all ages and abilities initiated challenges and difficulties that had to be addressed then and there. Thereby, teachers and instructors are encouraged to think creatively and find effective ways to deliver information. These challenges also opened doors to new methods that had to be adopted and tested to optimize education. Online learning support, accessibility, efficiency, evaluation, practical and theoretical approaches have taken part in the everyday life of instructors and teachers around the world. The pandemic can now be seen in a different light; a light of problem solving, where individuals are forced to find ways to deliver their work efficiently through the virtual world of possibility.

The challenges that art and design instructors at the University of Bahrain faced and the problem-solving techniques they attempted to employ were vital and came into play strongly and specifically with teaching the hearing-impaired students virtually.

The first section in this study contains the introduction. The second section explores the most effective international distance education practices and teaching strategies used to provide online art and design education for the deaf and hard of hearing (DHH). The third section evaluates and analyses hearingimpaired students' and their teachers' challenges and experiences of distance education in art and design. It concentrates on identifying the academic challenges of ten deaf and hard-of-hearing students who are enrolled in the BA Art and Design program at The University of Bahrain. It involves analysis of indepth interviews and action research conducted with two professors who have taught $\mathrm{DHH}$ students within the arts and design specialization at the University of Bahrain. It also analyses focus groups conducted by the researchers with the hearing-impaired students in order to investigate the challenges they encountered while teaching art and design content and skills remotely to these students, and to allow educators to benefit from their experiences and recommended approaches to overcome these challenges.

\subsection{Research Problem \& Significance}

There is a range of research papers that explored and recommended teaching strategies and alternative forms of assessment that can assist hearing-impaired students to learn through online learning platforms (Alsadoon \& Turkestani, 2020; Farhan \& Razmak, 2020; Krishnan et al., 2020; Mantzikos \& Lapp, 2020; Mingsiritham \& Chanyawudhiwam, 2020). These papers acknowledged that hearing impairment hinders students' ability to perceive information in the learning management systems and "requires the commitment of all stakeholders including researchers, designers, developers and academic decision makers to address these abilities." (Farhan \& Razmak, 2020, p.2). However, there are some specific strategies that are useful in teaching students with hearing impairments who are enrolled in art and design programs in higher education institutions, and which are yet to be explored and identified in literature. These art and design 
students and their educators may face additional challenges related to their discipline, which requires dealing with more advanced technical requirements, design considerations, and artistic needs. Therefore, there is a persistent need to understand these hearing-impaired students' and their educators' challenges, requirements, and preferences in order to improve their learning experiences through incorporating their needs within learning management systems. Understanding these needs, preferences and challenges will allow the designers and developers of learning management systems and e-learning platforms to embed features that will facilitate the online learning experience for deaf and hard-of-hearing students. According to Farhan \& Razmak (2020), designers and developers of e-learning systems must make it a priority to address the needs of hearing-impaired students in their interface and human computer interaction (HCI) designs.

In this research paper, which is based on a qualitative methodological approach, we aim to study the difficulties, challenges, and new techniques that facilitate effective methods for teaching the hearing-impaired virtually. The hypothesis raised in this study focuses on investigating the challenges of virtual learning faced by art and design DHH students and their instructors, and the effectiveness of the implemented approaches by instructors to optimise the students' learning experience. The objective is to better understand the difficulties and challenges of learning art and design through online tools used during the pandemic. The following research questions and objectives were used to guide the study in order to achieve its aim.

\subsection{Research Questions}

1. What are the distance-learning-related challenges faced by deaf and hard of hearing art and design students, and by their educators?

2. What are the most effective practices and strategies that art and design educators can employ to teach art and design hearing-impaired students remotely?

\subsection{Research Objectives}

1. To investigate the challenges faced by hearing-impaired art and design students while learning art and design online

2. To investigate the challenges faced by art and design educators while attempting to enhance and facilitate their hearing-impaired students' online learning experiences

3. To identify and recommend the most effective practices and strategies to enhance the virtual learning experience among hearing-impaired students in art and design distance education contexts

4. To understand hearing-impaired art and design students' needs and preferences in order to provide information that will help HCI designers design and develop an e-learning platform that is adapted to their preferences and needs. 


\section{Theoretical Overview}

Recently, the need for effective strategies to present educational content virtually through learning management systems (LMS) emerged unexpectedly in response to the COVID-19 pandemic. The need to explore, learn, and apply alternative teaching and learning approaches has created further challenges for hearingimpaired students and for their instructors. The common challenges that educators generally face during online education include anxiety due to technical problems, the lack of enough time for professional development, the time required to design and manage online courses and to upload their content, and the difficulty in adapting to students' varying levels in using technology (Bower, Dalgarno, Kennedy, Lee, \& Kenney, 2015; Rasheed, Kamsin, \& Abdullah, 2020 as cited in Alsadoon \& Turkestani, 2020). These challenges are exacerbated when teaching art and design remotely to hearing-impaired students, who already may have experienced challenges even with face-to-face education. Ibrahim et al. (2016) stated that although hearing-impaired students have a high tendency to study graphic design, they usually face the following challenges;

"Among them are the inefficient technology used for learning, negligence of deaf students' learning styles, and the sign language interpreters were not experts in graphic design field. Furthermore, a number of terms cannot be translated and thus led to misunderstanding. In addition, the available learning modules used were not tailored to the needs of deaf students" (Ibrahim et al., 2016, p.3)

The study conducted by Ibrahim et al. (2016) also revealed that the majority of deaf students who were studying graphic design in Malaysia reported that the most challenging courses are animation, illustration and web design, respectively.

McKeown \& McKeown (2019) identified three main challenges that DHH students face with online learning. These includes barriers related to accessing the learning management system, course materials, and communication.

A study by Alsadoon and Turkestani (2020) identified several challenges which might limit the use of a virtual classroom for hearing-impaired students. The study also identified some obstacles that educators faced while teaching these students remotely, during the Covid-19 pandemic. These obstacles included technical issues, difficulty in time-management, long translation time, "lack of simultaneous translation", and students' poor writing skills, which hindered their ability to clearly communicate in writing through the chat function in the LMS. In order to overcome some of these challenges, the 11 educators who participated in the study applied a number of approaches. One of the approaches involved sending the learning materials to the students as well as to the translators in advance before the virtual lecture. Another approach was to ensure that educators and students undergo training in using e-leaning platforms and LMS. The researchers also suggested that visual clues, such as looking confused or uncertain, help educators improve their teaching approaches. Another suggestion was to record the session for the translator, who can accurately and unhurriedly translate it for viewing at a time that was convenient for the students. It is also useful to show the students "content and information using images and videos with subtitles paired with sign language than word-based information" 
(Pappas et al., 2018; Alsadoon \& Turkestani, 2020, p.4). The researchers also recommended sending both students and translators the learning materials before the virtual lecture in order to allow them to familiarize themselves with the content and understand it easily.

The existing learning management systems in higher educational institutions require the integration of more visual and hearing assistive technology (AT) features that would allow students to study according to their unique abilities, needs, and preferences (Ibrahim et al., 2020). These systems should also easily allow users to customize the language of the interface because studies revealed that "DHH students have weaker English language skills than their hearing peers" (McClive et al., 2020, p.2). Unfortunately, many software HCI developers and designers are not aware of these needs and preferences (Farhan \& Razmak, 2020). Additionally, these developers and designers must also consider the perspective of educators, not merely for their hearing-impaired students (Farhan \& Razmak, 2020). Such special considerations are necessary and will help these students conduct tasks through interfaces that support their requirements. Therefore, Krishnan et al. (2020) think that it is important to modify and customise teaching practices and approaches to cater to them. They also believe that "these students may require educational programs customised to their unique needs during the pandemic" (Krishnan et al., 2020, p.109). Educators also need "to produce multimedia with greater content customization" (Baroni \& Lazzari, 2020, p.175). In an attempt to apply some of these customised considerations, Farhan \& Razmak (2020) developed a new e-learning interface with interactional features for use by students with hearing and visual impairments. The interface allows students to "place the cursor over content for it to be read aloud and/or to provide sign language." (Farhan \& Razmak, 2020, p.3). In Egypt, a gamified based elearning system was proposed by Shohieb (2019) for teaching DHH students. The system contains an avatar that interacts with students in Arabic Sign Language (ArSL). Shohieb (2019) believes that game-based learning may facilitate learning and communication for DHH students.

On the other hand, Bianchini et al. (2019) developed SWift (SignWriting improved fast transcriber), which is a web-based tool and transcriber that provides documents in a written form of any SignLanguage(SLs) transcription.In Bahrain, Fatima Al-Dhaen developed a program that converts scripts from SMS, E-mail or voice messages to sign language codes (Salman, 2017). Pappas et al. (2018) recommended that when designing e-learning systems for hearing-impaired people, it is important to consider the following recommendations and guidelines; replace the audio with visual tools like text, subtitles, pictures, and sign language; develop for hearing-impaired students an effective and comprehensible graphical interface that includes educational activities in a sequential manner; minimize the use of text as individuals who have a speech and hearing impairment exhibit clear limitations in reading comprehension. Many studies demonstrate that deaf individuals who communicate using sign language find it much easier to understand the meaning of a picture as opposed to written word (Pappas et al., 2018). Designers and developers of digital learning systems that cater to deaf and hearing impaired students must take into consideration these stated facts in 
addition to the directives of the Web Accessibility Initiative of the World Wide Web Consortium in order for the final product to be of optimal utility to the target audience (Pappas et al., 2018). They also recommended the use of examples, practice queries and feedback as well as short and wide-ranging micro-modules to convey educational content to hearing-impaired students. According to them, one of the key takeaways when developing educational content for this unique target audience is to minimize the use of text and rely on the key word strategy to attract their attention.

Additional aspects to consider include hearing-impaired e-learning preferences. Pappas et al. (2018) suggested that hearing-impaired users prefer to use smartphones in comparison to computers or tablets. The study also indicated that they mostly prefer to engage on social media when they are online. They also prefer to use "e-mail and read news and blogs, whereas more rarely they spend time on e-learning activities, e-banking, entertainment and e-government services" (Pappas et al., 2018, p. 10).

Additional challenges and barriers that hearing-impaired students and their instructors face during e-learning were identified by Farhan \& Razmak (2020). These include limited access to high speed internet, the time and financial and technical support needed to develop e-learning systems and content, educators' lack of technological skills and their resistance to the use of technology. To overcome these challenges, Farhan \& Razmak (2020) recommended that universities provide the IT infrastructure (Internet speed, hardware and software) required by educators and students to facilitate their use of e-learning platforms. They also recommended that universities offer faculty members financial incentives and psychological motivation.

One of the challenges identified by Krishnan et al. (2020) is that hearing devices do not accurately detect sounds during online lessons. They also found that lip reading through the screen requires more focus and effort.

Adding captions, sign language overlays, and subtitles to videos can help minimize some of the challenges. There are online tools and platforms that allow educators to add subtitles to videos such as Kapwing, YouTube, and Veed. Additional useful resources and applications that can support distance learning for students with hearing impairments are listed and described in Table 1.

Table 1: Examples of useful resources and applications that can support distance learning for students with hearing impairments

\begin{tabular}{|l|l|l|}
\hline $\begin{array}{c}\text { Tools/Applications/ } \\
\text { Resources }\end{array}$ & \multicolumn{1}{c|}{ Description } & \multicolumn{1}{c|}{ Link } \\
\hline Kapwing & $\begin{array}{l}\text { Kapwing is a content creation tool } \\
\text { that allows instructors to create } \\
\text { and edit videos. It is also a digital } \\
\text { storytelling online platform. }\end{array}$ & https://www.kapwing.com/ \\
\hline Veed & $\begin{array}{l}\text { Veed allows users to autogenerate } \\
\text { subtitles or add subtitles to their } \\
\text { video tutorials. }\end{array}$ & https://www.veed.io/auto-subtitle \\
\hline
\end{tabular}




\begin{tabular}{|c|c|c|}
\hline $\begin{array}{l}\text { Tools/Applications/ } \\
\text { Resources }\end{array}$ & Description & Link \\
\hline Google Meet & $\begin{array}{l}\text { Google Meet allows instructors to } \\
\text { enable captioning while teaching }\end{array}$ & $\frac{\text { https://support.google.com/meet/a }}{\underline{\text { nswer/9300310 }}}$ \\
\hline Google Slides & $\begin{array}{l}\text { Google Slides allows instructors to } \\
\text { enable captioning while teaching }\end{array}$ & $\begin{array}{l}\text { https://support.google.com/docs/a } \\
\underline{\text { nswer/9109474?hl=en }}\end{array}$ \\
\hline Screencast-O-Matic & $\begin{array}{l}\text { Screencast-O-Matic allows } \\
\text { instructors to record their } \\
\text { presentations for students to watch } \\
\text { on their own. This helps } \\
\text { instructors allocate more time for } \\
\text { interaction during the online } \\
\text { lecture. }\end{array}$ & https://screencast-o-matic.com/ \\
\hline Screencastify & $\begin{array}{l}\text { Screencastify is a screen recorder. } \\
\text { It is an extension of Google } \\
\text { Chrome that allows instructors to } \\
\text { record video of their screens or } \\
\text { with their webcams. }\end{array}$ & https://www.screencastify.com/ \\
\hline $\begin{array}{l}\text { G-Suite } \\
\text { Accessibility Guide }\end{array}$ & $\begin{array}{l}\text { This is a guide to Google's built- } \\
\text { in accessibility settings and } \\
\text { features }\end{array}$ & $\begin{array}{l}\text { https://support.google.com/a/answ } \\
\text { er/1631886?hl=en }\end{array}$ \\
\hline $\begin{array}{l}\text { Chromebook } \\
\text { Accessibility Guide }\end{array}$ & $\begin{array}{l}\text { This is a guide to Chrome's built- } \\
\text { in accessibility settings and } \\
\text { features }\end{array}$ & $\begin{array}{l}\text { https://edu.google.com/why- } \\
\text { google/accessibility/chromebooks- } \\
\text { accessibility/?modal_active=none }\end{array}$ \\
\hline $\begin{array}{l}\text { Teach from } \\
\text { Anywhere }\end{array}$ & $\begin{array}{l}\text { This is a "Google-led initiative" } \\
\text { that gives educators tips on e- } \\
\text { learning, and allows them to Join } \\
\text { Educator Groups to share their } \\
\text { experiences with others. }\end{array}$ & $\begin{array}{l}\text { https://teachfromanywhere.google/i } \\
\underline{\text { ntl/en/\#for-teachers }}\end{array}$ \\
\hline
\end{tabular}

Baroni and Lazzari (2020) noted that in one of Italy's educational establishments, instructors were given tutorials, guides and training and were then asked to create interactive multimedia content while adhering to the following standards and considerations:

- Using all available messaging methods, as per the standards of multimedia learning;

- Including short exercises based on sound and video (no more than 8 minutes), which are clear, comprehensive, and with sufficient emphasis on messaging, as per current suggestions on the design of distance learning by UNESCO (2020);

- Educators have to be observed on video to clarify the nature of the assignment and breakdown complex ideas, in order to escape the need for physical interactions with students; 
- Using captions and sign language to ensure comprehensive reach allows for the avoidance of independent solutions for deaf students as indicated by the Universal Design for Learning(UDL) approach, which requires: numerous methods for portraying the educational content by instructors, numerous methods of articulation by students, and numerous methods to capture the attention of students;

- Ensuring comprehensive reach depends on having digital content (either proprietary of from other online sources) that has sufficiently coherent verbal content without background music, and with captions;

- Having the proper focus on the face (especially the eyes and mouth to ease lip reading and detection of expressions) or the rest of the body (from the head to abdomen) where signs are explained;

Osman (2020) indicated that special needs students benefited from an integration program covering several specializations in Sultan Qaboos University. The university was very focused on the needs of this challenged group of students. These students could utilize the services of the Department of Students with Disabilities which offers numerous assistive technologies such as Nvda screen reader, Index Everest v5, Natiq Reader, Braille display, OCR software for PDF reading, Text to speech software, etc (Osman, 2020). Furthermore, the university requested all instructors of online courses which are available to students with special needs to modify the educational material. According to Osman (2020), some of the course design guidelines that were communicated to the instructors were as follows:

- Use PDF files which were converted from word documents, and refrain from using PDF files which are scans of a printed document.

- Offer a text-based explanation for any images of graphical elements.

- Include sub-titles and captions if the course material includes videos.

Despite all the above-discussed literature review, there is still lack of research conducted on the challenges faced by hearing impaired students who study art and design in higher education institutions through distance learning during the Covid-19 pandemic. The next section explores these challenges, and discusses possible approaches to overcome them.

\section{Research Methodology}

In order to achieve the objectives of this study, observation, in-depth interviews with academics and focus group discussions with hearing-impaired students at The University of Bahrain were used to collect data for this study. This investigation attempts to explore and recommend effective and innovative approaches to teach art and design hearing-impaired students remotely.

The methodological basis of our research is qualitative action research as it is considered an inquiry approach appropriate for describing, analysing, and observing social behaviors (Caupayan \& Pogoy, 2021). 


\section{Sample Size and Participants}

A total of ten students (five males and five females) participated in this qualitative study. The students were enrolled in the BA Art and Design Program at The University of Bahrain. This sample was purposively selected because they were the first batch of $\mathrm{DHH}$ students in the Art and Design program. The students have completed two years of orientation and were in their first year of the bachelor program when they participated in this study. Their ages ranged between 24-26 years. All the participants were completely deaf and mute and their primary mode of communication was the Arabic Sign Language (ASL).

The data used in this study was collected through interviewing, observing, and receiving weekly progress reports from two art and design lecturers who taught deaf and heard-of-hearing students remotely. In addition, ten hearing-impaired students (five females and five males) and a translator were also interviewed. Thus, data triangulation was applied through the employment of different data collection instruments in order to validate the qualitative analysis. Prior to joining the University of Bahrain (UOB), the students were integrated into public schools by the Ministry of Education. They completed their secondary studies at the end of the 2017-2018 academic year and started their university studies at the University of Bahrain at the Ministry's expense.

\section{Data Collection Instruments}

This action research was conducted at the University of Bahrain throughout the second academic semester of 2019-2020 during the COVID-19 pandemic. Data was mainly collected through an action research-based study and observation of the academic performance and experiences of ten art and design hearingimpaired students (five females and five males) and their instructors, and an analysis of the challenges that the students and their instructors faced. Data was also collected through interviewing two instructors who teach hearing-impaired students who are enrolled in the BA Art and Design program, in addition to an interview with the interpreter. As part of the action research, both educators provided weekly input through writing a short report about the progress of students after each lecture. The first instructor is specialized in Ceramics and Fine Arts, and she taught them a course titled "Fundamentals of Design". The second instructor is specialized in Fine Arts and Art Psychotherapy, and she taught them a course titled "Drawing Techniques". In addition, semi-structured interviews were conducted with the ten hearing-impaired students. The interviews were virtually conducted through Microsoft Teams and WhatsApp by a senior hearingimpaired Art and Design student, who is in her last year in the program. They were then transcribed by her and other students enrolled in the program. Thus, the study is mainly a reflective practice, which involved conducting systematic enquiries in order to help the researchers and their colleagues in addition to art and design instructors in general improve their own academic practices. The interviews with the instructors revolved around three main themes including their experiences in teaching the hearing-impaired students virtually, the obstacles they faced, and their insights on approaches that could be applied to improve the e-learning environment and online teaching strategies for art and design hearing-impaired students. On the other hand, the interviews with the students entailed 12 questions revolving around the following topics: 
- The experience of learning art and design from a distance

- The main challenges and difficulties faced during distance learning

- The pros and cons of learning art and design remote remotely

- The teaching strategies and assessment methods that the educators employed and that students considered effective in teaching art and design remotely

- The difficulties in communicating with the instructors remotely

- Their views on the translator's performance in the online learning environment

- Their perceptions and preferences in relation to the experience of traditional learning versus distance learning

- The digital tools and applications that students considered most effective in helping them learn art and design remotely

- Their insights and suggestions in terms of what the university should provide in order to facilitate and improve their distance learning experience

\section{Data Analysis and Discussion}

The two instructors who participated in this research were asked about the main challenges they faced during distance learning with deaf and hard-of-hearing students. In addition to the challenges, the interview questions focused on the efficacy of virtual/remote learning, their concerns in relation to the delivery of the theoretical and practical content of their courses, the pedagogical strategies they employed, and their proposed modifications and recommendations to make the learning experience more effective and successful. The ten hearing-impaired students' experiences, challenges and needs were also addressed through the interviews conducted by the senior students and through an analysis of the two instructors' weekly reports. The main challenges that both parties faced included communication barriers, misinterpretation of tasks, and difficulty in fulfilling the course intended outcomes.

The DHH students in both courses highlighted the following important challenges:

- Difficulty in understanding the instructors' written feedback regarding assessments

- Difficulty in understanding projects that rely on creative thinking in terms of instructions and requirements

- Difficulty in fulfilling and understanding theoretical concepts and how to apply them practically in a project or an assignment

- Difficulty in written communication and projects that require research

- Difficulty in fulfilling tasks that require persuasion and communication skills

Thus, the main challenges faced by the DHH students mainly revolved around theoretical and practical information that relied heavily on artistic terminology and research which affected their performance. The above-mentioned challenges became clear when looking at the average results of grades which were assessed against the course intended learning outcomes (CILOs) in Tables 1 and 2, and mapped to the following intended learning outcomes (PILOs) of the BA Art and Design program: 
a. Produce creative and innovative artworks that reflect influential social issues and combine technical and artistic skills considering the principles and elements of design, color theory, and aesthetic values as applicable

b. Create effective and influential artworks that employ the contemporary technology needed in the labour market

c. Gain adequate knowledge of artistic research methods in the field of arts and design through conducting research and studies that reflect students' understanding of the economic, historical, political, artistic, and philosophical concepts and other aspects of humanity

d. Gain professional and functional expertise that qualifies students to work and pursue postgraduate studies in the fields of art and design and related topics

e. Acquire communication and persuasion skills for presenting artistic ideas and achievements in contexts of collective criticism and commenting on artistic projects both in theory and in practice

f. Acquire the skills of self-development and independent learning in the fields of art and design to achieve awareness of the importance of lifelong learning

g. Demonstrate adequate awareness of the ethics of artistic work and a full understanding of the cultural, social, legal, and psychological values that characterize society

Table 1: The percentage of fulfillment of Course Intended Learning Outcomes (CILOs) of Drawing Techniques 1 mapped with the Program Intended Outcomes (PILOs)

\begin{tabular}{|c|c|c|c|c|c|c|c|c|}
\hline \multirow{2}{*}{\multicolumn{2}{|c|}{ CILOs }} & \multicolumn{7}{|c|}{ PILOs } \\
\hline & & A & B & C & D & E & $\mathbf{F}$ & G \\
\hline CILO 1 & $\begin{array}{l}\text { To acknowledge the } \\
\text { various media of drawing } \\
\text { and their practical use }\end{array}$ & $79 \%$ & NA & $79 \%$ & $79 \%$ & NA & $79 \%$ & $79 \%$ \\
\hline CILO 2 & $\begin{array}{l}\text { To understand the } \\
\text { theoretical and practical } \\
\text { principles of drawing } \\
\text { through the media and } \\
\text { themes included in the } \\
\text { course }\end{array}$ & $79 \%$ & NA & $79 \%$ & $79 \%$ & $79 \%$ & $79 \%$ & $79 \%$ \\
\hline CILO 3 & $\begin{array}{l}\text { To apply the fundamentals } \\
\text { of shadow and light in } \\
\text { artworks by using pencils, } \\
\text { charcoal, and ink }\end{array}$ & $79 \%$ & NA & $79 \%$ & $79 \%$ & NA & $79 \%$ & $79 \%$ \\
\hline CILO 4 & $\begin{array}{l}\text { To create drawings that } \\
\text { are based on the accuracy } \\
\text { of details }\end{array}$ & $79 \%$ & NA & & $79 \%$ & NA & $79 \%$ & $79 \%$ \\
\hline CILO 5 & $\begin{array}{l}\text { To know the basics of } \\
\text { human anatomy } \\
\text { proportions in traditional } \\
\text { art by using a variety of } \\
\text { pencils }\end{array}$ & $69 \%$ & NA & $69 \%$ & NA & NA & $69 \%$ & $69 \%$ \\
\hline CILO 6 & $\begin{array}{l}\text { To analyze artworks } \\
\text { verbally in an efficient and } \\
\text { constructive manner }\end{array}$ & NA & NA & NA & NA & NA & NA & NA \\
\hline
\end{tabular}


Table 1 shows the percentages of fulfilment of CILOs of the Drawing Techniques 1 course taught by Instructor A. The results reveal that the intended learning outcomes which focus on theoretical approaches in columns B and $\mathrm{E}$ are the most challenging to DHH students. The PILO in column B relies on creating influential artworks which entail research and presentations, and the PILO in column E also relies on presentations but mostly on communication and persuasion skills. The nonapplicable (NA) cells shown in the table indicate that the students were not assessed on certain learning outcomes because of their inability to communicate verbally and present coherently written research and critiques due to their hearing-impairment. The table clearly shows the challenges faced by DHH students and thereby communicates their needs, which could be met by modifying the course intended learning outcomes to suit their needs, and possibly by creating a modified version of the program intended learning outcomes and project specifications for $\mathrm{DHH}$ students.

Table 2: The percentage of fulfillment of Course Intended Learning Outcomes (CILOs) of Fundamentals of Design mapped with the Program Intended Outcomes (PILOs)

\begin{tabular}{|c|l|c|c|c|c|c|c|c|}
\hline \multicolumn{2}{|c}{ CILOs } & \multicolumn{5}{c|}{ PILOs } \\
\cline { 2 - 8 } CILO 1 & $\begin{array}{l}\text { To create designs that } \\
\text { incorporate and apply } \\
\text { principles and elements of } \\
\text { design }\end{array}$ & $60 \%$ & NA & NA & $60 \%$ & NA & NA & $60 \%$ \\
\hline CILO 2 & $\begin{array}{l}\text { To understand important } \\
\text { design terminology and } \\
\text { principles, and concepts of } \\
\text { painting and visual } \\
\text { communication }\end{array}$ & NA & $54 \%$ & $54 \%$ & $54 \%$ & NA & $54 \%$ & NA \\
\hline CILO 3 & $\begin{array}{l}\text { To contribute in solving } \\
\text { societal issues by } \\
\text { employing the elements } \\
\text { and principles of } \\
\text { composing artistic works }\end{array}$ & $36 \%$ & NA & $36 \%$ & $36 \%$ & $36 \%$ & $36 \%$ & NA \\
\hline CILO 4 & $\begin{array}{l}\text { To understand, analyze } \\
\text { and critique artistic works }\end{array}$ & NA & $45 \%$ & $45 \%$ & $45 \%$ & $45 \%$ & $45 \%$ & $45 \%$ \\
\hline CILO 5 & $\begin{array}{l}\text { To distinguish between the } \\
\text { various materials and } \\
\text { techniques that are used in } \\
\text { design }\end{array}$ & $60 \%$ & NA & $60 \%$ & $60 \%$ & NA & $60 \%$ & $60 \%$ \\
\hline
\end{tabular}

Table 2 shows the results of the theoretical course that was taught by Instructor B. The results clearly express the difficulty in fulfilling most of the course intended learning outcomes. The DHH students' comprehension, response, and interaction were hindered as a result of the difficulties and complications that they faced in achieving tasks that required writing and reading skills. This is especially exacerbated when the subject taught is a theoretical one. The CILOs and PILOs that are not applicable (NA) highlight the written communication challenges faced by $\mathrm{DHH}$ students, therefore requiring the instructor to omit certain 
assessments to better suit their needs and capabilities. The cells that indicate low percentages show that the instructor did assign tasks that match the learning intended outcomes, but the results show that the average grades received by the students were low and therefore those specific intended learning outcomes of the course and program were not met. Accordingly, in trying to optimize the learning experiences of DHH students, educators must focus on finding ways to resolve the theoretical and communication challenges faced by the students.

According to Instructors $\mathrm{A} \& \mathrm{~B}$ it is important to emphasize that miscommunication is the foundation of most of the challenges they both faced. The challenges discussed will be followed by recommendations focusing on optimizing distance learning for $\mathrm{DHH}$ students, especially in art and design learning contexts. These challenges pertain to the following:

- The instructor's possible lack of understanding of the nature of sign language to deliver the needed in terms of project requirements through the interpreter;

- The instructors' difficulty in understanding the questions asked by the students through the interpreters' explanation regarding their assessments;

- The communication barrier and inability to understand the scope of an art project, which affects the student's motivation and concentration;

- The interpreter's possible lack of understanding of the terminology and concepts in art and design content;

The delivery of information related to courses, assignments and projects was a major obstacle faced by Instructors A \& B. It was noticeable that the $\mathrm{DHH}$ students did not fully comprehend the information and project specifications explained during lectures, which was caused by misinterpretation between the instructors and the interpreter through virtual learning. Having an interpreter who is aware of artistic and graphic terminology and applications is a necessary component to delivering the right information to an art and design DHH student. It is vital because the student's understanding and interaction with the subject is interconnected with the information given by the interpreter. Therefore, the process of e-learning to these students is dependent on the clarity and connection of a three-way communication cycle between the interpreter, the instructor and the student.

The first challenge revolves around the importance of understanding the major components in sign language by the instructor. The initial step to this understanding would be to acknowledge the full definition of the language. Sign language is defined as: "any various formal languages employing a system of hand gestures and their placement relative to the upper body, facial expressions, body postures, and finger spelling especially for communication by and with deaf people." (Merriam-Webster's Dictionary, 2021)

The definition highlights an important aspect especially with virtual learning. The visibility of the interpreter's upper body, the clarity of the webcam, and the pace of the interpreter's gestures are all components that strongly affect the student's understanding. Likewise, if the instructor is talking rapidly while the internet connection is bad, this would complicate the interpreter's understanding, which 
in turn complicates the students' learning. This is an important point as stated by Instructors A's experience, where she had to remind the interpreter to fix the camera angle for upper body visibility to ensure the delivery and clarity of information to the students. It would be important for the instructor to slow down his/her language, and also modify instructions to be more descriptive, rather than concise.

It is also important to note that there are several systems of deaf sign-languages that are employed in different parts of the world, such as the American Sign Language (ASL), the British sign language (BSL), and the Arabic Sign Language (ArSL). In this paper, the sign language involved is the Arabic Sign Language (ArSL). The ArSL was developed in 2004 by the Arab Ministers Social Affairs (CAMSA) to unify the MENA region with one distinctive sign-language to be understood in the region (Samir \& Tolba, 2015). Another important aspect regarding the dynamics of deaf sign languages in general is to understand that it is a descriptive language. For example, instead of saying "create a drawing of the sunset with two warm colors", it would be clearer to say, "with a pencil that is red, a pencil that is orange, draw the sun on a white paper". This would also ease the interpreter's explanation to the students.

The second challenge is the difficulty faced by students in understanding the instructor's written feedback regarding their artwork in general. In order to comprehend and analyse the dimensions of this challenge, it is important to understand that writing is considered as a second language to the deaf student, perhaps even a foreign one. It is also vital to understand that the student's ability to read and write varies considerably from one student to another. One student may have better skills in writing and reading, while the other does not. These aspects are crucial for the instructor to be aware of as they would be able to feed into the effectiveness of delivering information whether by writing or via the interpreter.

To explain this challenge in a clear manner, one might need to focus on the student's style of communicating via typed words/text. This would indicate their comprehension level in reading and writing. This is a crucial matter not only to the visual arts but to education in general in terms of inclusion and clarity of communication. Instructor B stated that it is important to prolong the explanation in lectures, especially when the student has difficulty in following or understanding the interpreter. Additionally, Instructor B, who taught a theoretical course, expressed the noticeable lack of response and interaction caused by the language barrier, which consequently hindered the dynamics of teaching. The instructor noticed that the students were not able to understand the material that was interpreted by the translator. In such cases, it would be beneficial for the instructor to simplify the information of the lecture and give present it to the interpreter. Since sign language is a descriptive language, as mentioned earlier, the interpreter would need to understand the information before trying to translate it to students. This also connects with the importance of changing the written language from "normal" to descriptive to ensure that the students understand it. Writing in a descriptive manner also proved to be 
beneficial when it was paired with breaking down sentences to a basic level without using pronoun or terms that might need translation. This would also help the instructor to deliver information that would instigate and motivate the students via ease of communication to perhaps satisfy the requirements of various art and design projects or assignments. Furthermore, Instructor A suggested the need for instructors who teach deaf and hard-of-hearing students to be familiar with sign language. This suggestion, she claims, would minimize the miscommunication and the challenges mentioned. Instructor B agrees with this suggestion but emphasizes the necessity for students to have reading and writing skills to fully comprehend and be integrated into every aspect of the course in general. She also highlights the necessity of the interpreter's understanding of the contents of the lecture beforehand to minimize miscommunication. These suggestions are important to ensure the students' full grasp of the course, and to minimize their frustration.

Both instructors also stressed the importance of patience when communicating to the students in terms of messages on platforms like Microsoft Teams, WhatsApp, and Blackboard. This recommendation was based on the instructors' experience as they both noticed that students continuously need to ask questions. According to the instructors, this is a factor that is important to focus on, as it will eliminate frustration and give the students a sense of safety in being understood by the instructor. Furthermore, Instructor B highlighted the importance of avoiding long lectures, and replacing the extensive detail in verbal communication with clear, basic, and descriptive communication. It is useful to note that the art and design studio courses usually involve long lecture hours due to their practice-based nature. This was an aspect that was raised by Instructor B who suggested dividing the one lecture per week into two shorter lectures, which would benefit the students in comprehension, motivation, and productivity.

Considering the aforementioned challenges, it is important to understand that the main difficulty is the language or communication barrier. These challenges were discussed in meetings and reports between the instructors teaching hearingimpaired students in the art and design course. Instructors agreed that the motivation of the students exists, however the hinderance is caused by the interpreter's lack of understanding art and design terminology and the detailed practical instructions and artistic as well as technical specifications of projects/assignments. This has been noticed by the students' submissions of certain projects. Instructor B also noted that it would be of considerable benefit to the student, if the instructor would provide the information to be given to the student a day or two before. This will give the interpreter time to understand and inquire about aspects that require clarification.

It is worthy to note that the students express a desire to further their development, both theoretically and practically, in the field of art and design. This was supported in the reports of both Instructor A \& B, who noted that many of the students were highly motivated, while others needed encouragement and support in terms of understanding their strengths, weaknesses, and guidance for improvement. This again highlights the importance of creating a modified 
learning approach to the deaf and hard-of-hearing students which will enable them to successfully progress in the field of art and design. One of the crucial aspects mentioned by Instructor A, was the need for one-on-one meetings with the students to be able to measure the extent of the student's understanding and level of motivation. This would require the instructor to give individual feedback to each student in an attempt to minimize frustration and de-motivation caused by the language or communication barrier.

This proves to be beneficial only when the feedback consists of basic vocabulary that the student may understand. Giving feedback to art and design students remotely is generally not easy as it requires pointing at the design or artistic elements that require further improvement. This difficulty is augmented when the students are deaf and hard-of-hearing and when the instructors do not have a background in sign-language. That in itself further impedes the understanding of feedback given and received from both parties. Although there are tools that may be helpful such as the pointer and pen drawing feature in Blackboard for pointing at specific elements that the instructor displays on the screen, these tools usually disappear from the instructor's interface when a student shares the screen.

On the other hand, Instructor B noted the effect of the student's interest in art and design as an important aspect that contributes to stimulating the potential creative capabilities of the student. This, in turn, sheds light on the enthusiasm and openness that students have toward the theoretical and practical aspects of the art and design course in the University of Bahrain. This also highlights the importance of creating a modified learning approach to deaf art and design students, where information would be correctly delivered to them by both the interpreter and the instructor. In light of this, it might be necessary for the instructor to have a background in sign language or pursue a sign language course. This would mainly be beneficial for the deaf students who would have the chance to be directly understood by the instructor and vice versa. Similarly, it is important for the interpreter to also have an art and design understanding in terminology, applications, theories, etc. In addition, regular meetings between art and design interpreters and instructors may yield new approaches through discussing experiences, challenges, learning strategies which could benefit the deaf students and optimize their learning.

Instructors A \& B were also asked to provide their input regarding their experience with the interpreter's performance. They both highlighted the important active role of the interpreter in the teaching process. However, they recommended that the interpreter would add more value to the teaching process if he was knowledgeable about the field of art and design and its components and terminology to ensure the accurate delivery of information. Instructors mentioned that the communication between them and the interpreter mostly revolved around explaining certain terms or techniques, to ensure that the students understand the content. Yet, this did not seem to yield significant results with the students. Perhaps a more effective way to approach this challenge would be to set a compulsory workshop for the interpreters to be able to understand important terms and applications in the art and design field. 
An interview was conducted with the interpreter who highlighted the challenges that he faced regarding the accurate delivery of information and interpretation of the information that was at hand. This reverts to the importance of hiring an interpreter in the art and design field to be knowledgeable about the content and terminology of the designated course/module. The interpreter worked diligently in using descriptive interpretation from the instructor to ensure the accuracy and clear delivery to the students. More so, the interpreter stated the importance of preparing the artistic terminology and outlines by the instructor to be reviewed by him before the lecture in order to ensure accuracy in his interpretation.

Furthermore, both instructors expressed their views about the effectiveness of distance learning platforms with deaf and hard-of-hearing students in the art and design field. Instructor A stated that the used platforms, which were mainly Microsoft Teams and WhatsApp, were effective in facilitating the communication between the instructor and the deaf students. Students were able to reach out to the instructors when certain matters regarding assignments, projects, and feedback arise. The students could easily submit their work through the mentioned platforms, and the instructor would respond via comments sent to the interpreter, who will in turn deliver the comments to the student. Nevertheless, both Instructors A and B noted that the primary challenge faced regarding the elearning platforms or learning management systems (LMS) was the students' difficulty in submitting assignments. This may be considered a technical obstacle that could be solved by giving the students workshops prior to the commencement of the semester in order to clarify how to use these platforms and any other effective applications and resources especially for learning art and design content, and for sharing digital and graphic materials.

In an attempt to overcome some of the above-mentioned challenges, the instructors explored some approaches. Instructor A \& B were able to target the difficulties that students faced and have accordingly applied modifications to the assignments and projects. These modifications, both theoretical and practical, included simplifying the projects' instructions and requirements, with supporting media (images, videos) that would be understood by the students via the interpreter (Figure 1).

Instructor A was responsible for teaching a practice-based course titled "Drawing Techniques" to hearing-impaired students. The module aims to develop the students' drawing skills and techniques through different themes. When the instructor assigns a project or an assignment, she would describe the theme, the art materials that needed to be used and the required size of the paper. Then she would usually give examples of the expected level. It was repeatedly noticed that the students copied or drew the examples given rather than creating their own composition in an art project. This reflects a severe gap in miscommunication between the instructor, the interpreter, and the student. This awareness clarifies the low creative performance that was depicted in the students' work 


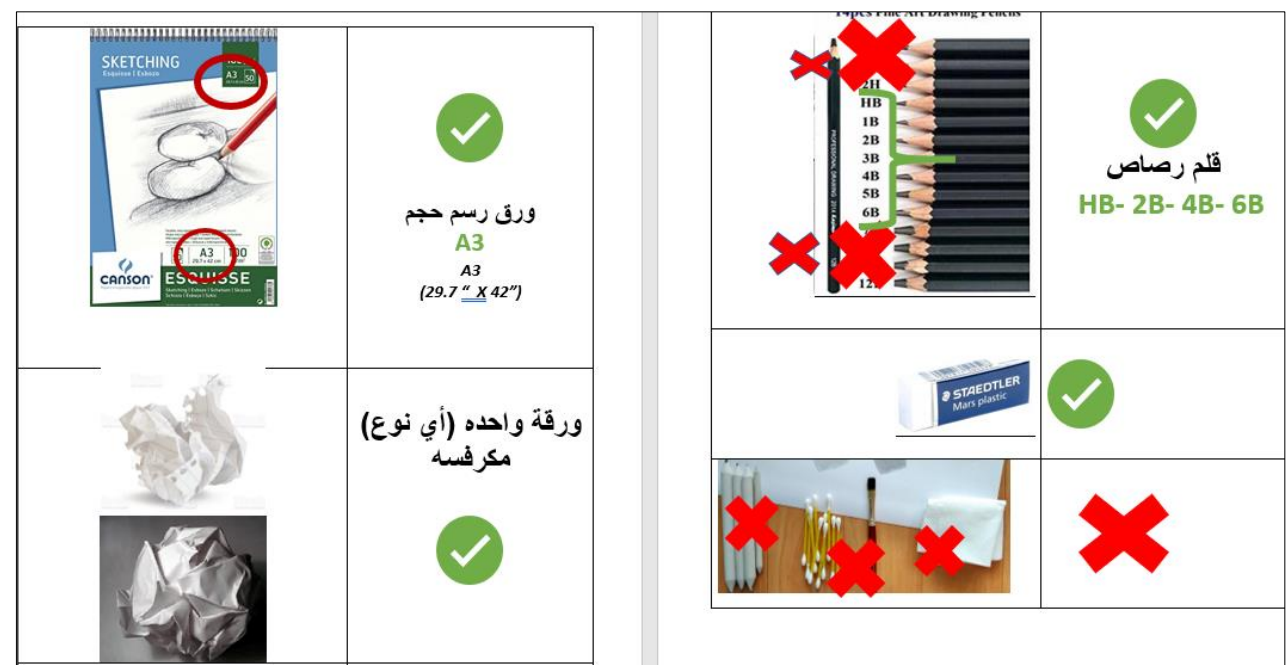

Figure 1: Instructions with images as an approach to clarify the assignment and the needed mediums

In an attempt to overcome the challenges related to students' misunderstanding of the written instructions and guidelines for an assignment, Instructor A replaced the written instructions with images, and presented a video to show the process, step by step. The assignment was to crumble a piece of white paper and place it in front of them. This observational task also had limitations as to what kind of pencil to use, refraining from any blending tools, and focusing on drawing what is seen as observed. Figure 1 shows the visual instructions and materials to be used. The instructor also recorded a video that started with showing all the materials needed and the process. In addition, an example was provided by the instructor. The submission of most students was a copy of one of the two examples given as shown in Figure 2 (Drawing A); the instructions were not understood but the skill expresses motivation and focus. However, a few other students fulfilled the requirements of drawing from observation as shown in Figure 2 (Drawing B).
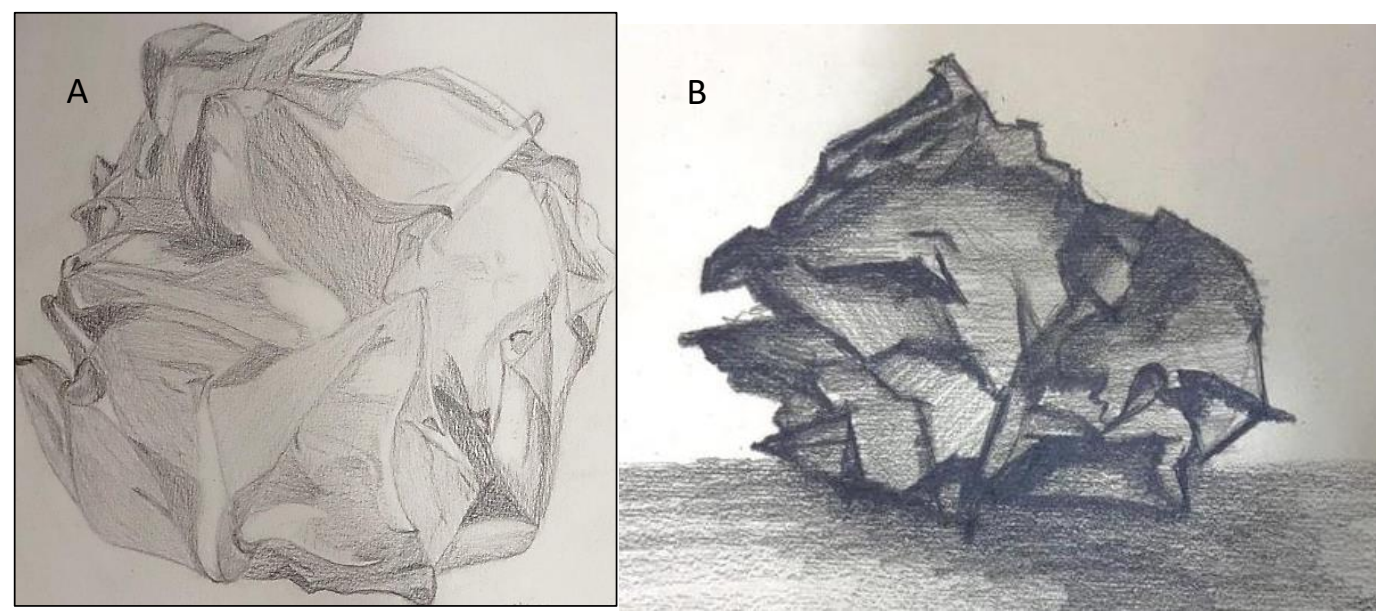

Figure 2: DrawingA represents incorrect crumpled paper assignment; The student copied the example.DrawingB represents correct crumpled paper assignment; The student did not copy the example

As mentioned by Instructor A, the assignments and projects were modified based on what she believed was the best approach to develop the students' drawing 
technique. This approach involved asking them to draw from the references that were provided with each assignment. However, Instructor A noted that one assignment fulfilled the independent creative level, which was drawing a selfportrait by taking a "selfie" and drawing it. The project consisted of two parts; the first was for the student to take 4 different expressions of his/her eyes; the second a selfie with an unusual expression. These were to be drawing with pencil. The results were pleasing to the students as it was one of the projects that required skills beyond "copying". The instructions for this project, were acted by Instructor A on camera, step by step. Two of the examples of the students' results are shown in Figure 4 (Selfie) and Figure 5 (Eye Expression Studies).

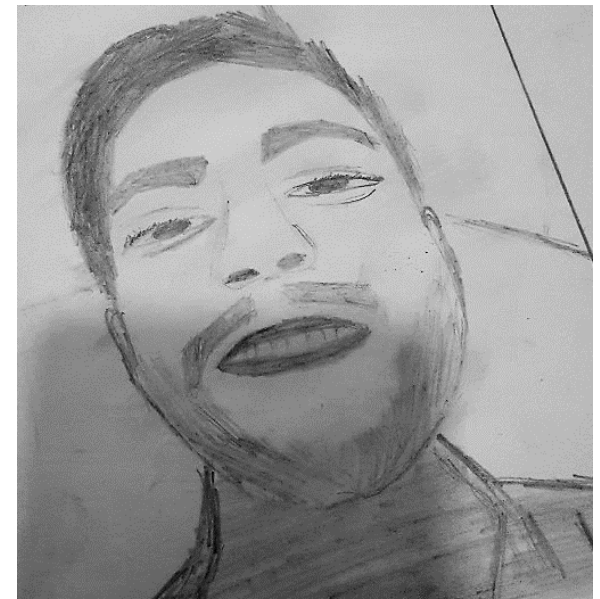

Figure 1: Selfie of student (independent creative approach)

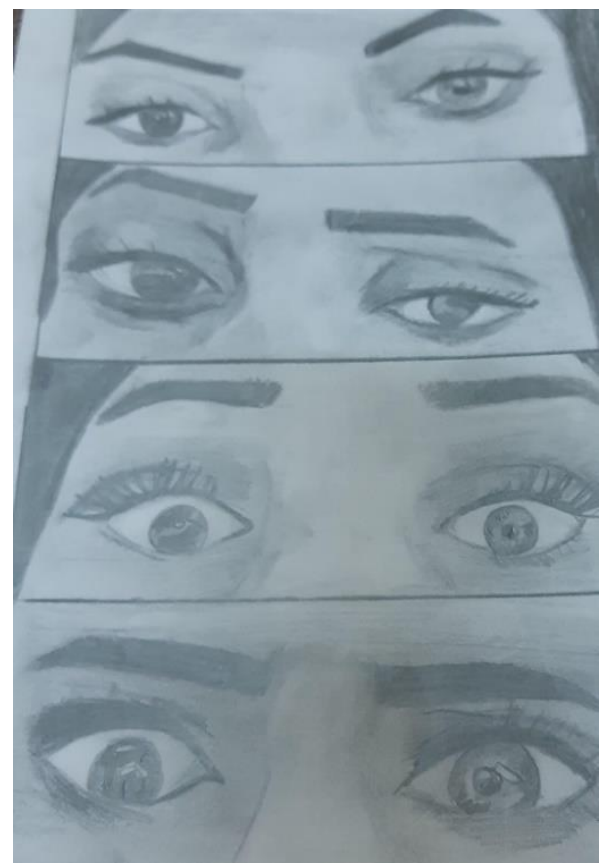

Figure 2: Eye expression drawings by one of the students (independent creative approach)

The instructors indicated that creative thinking, confidence in their work, and being able to challenge themselves are vital factors that can facilitate the students' 
learning experience. Both instructors stated that when they noticed the strength and motivation of the students in their ability to produce a drawing from a study of another image, or begin to think creatively, it affected and drove their own motivation and allowed students to challenge themselves in wanting to exert more effort in order to develop their skills. Most of the students perhaps did not get the right care or attention in terms of art and design education. So, it is the duty of their instructors and of any a nurturing educational organization to provide them with ways to reach their full potential.

\section{Conclusion and Recommendations}

This paper reported on an investigation of the challenges educators who teach art and design deaf students at The University of Bahrain (UOB) faced while trying to teach them remotely. The findings of this study revealed that the main challenges revolved around miscommunication between the instructor and the interpreter, which affects the delivery of information to the student. Another main challenge was the interpreter's lack of knowledge in the field of art and design, resulting in misinterpretation of the assignments that would hinder the student's comprehension. The educators' insights from the interviews, action research, and literature review have allowed for a more robust depiction of the most effective approaches and recommendations to teaching hearing-impaired students in a virtual art and design classroom. These recommendations include directing the students and their instructors to the concept of learning management and to the preparation in advance of the learning materials, sharing captioned materials before each lecture, encouraging self-learning among the students, and encouraging them to communicate and inquire about information. Additionally, instructors need to understand that sign language is descriptive, hence the need to modify the instructions given to the student in a basic manner that would be understood by the interpreter and the student. Furthermore, it is essential to brief the interpreter with art and design terminology to ensure the accuracy of interpretation. It is also important to continuously evaluate and improve educators' approaches for implementing distance learning through obtaining the necessary feedback from students and their family members in order to overcome any challenges. In addition, existing learning management systems need to be upgraded to support the needs and preferences of deaf and hard-of-hearing students who in a virtual art and design classroom. It is important to add features on the existing LMS' interfaces that are not available in traditional e-learning systems. All the aforementioned recommendations may enhance the educational outcomes for hearing impaired students and minimize the challenges faced by them and their instructors.

\section{References}

Alsadoon, E., \& Turkestani, M. (2020). Virtual classrooms for hearing-impaired students during the coronavirus covid-19 pandemic. Revista Romaneasca Pentru Educatie Multidimensionala, 12(1Sup2), 1-8. https:/ / doi.org/10.18662/rrem/12.1sup2/240

Baroni, F., \& Lazzari, M. (2020). Remote teaching for deaf pupils during the covid-19 emergency. In M. B. Nunes \& P. Isaias (Eds.), Proceedings of the IADIS Conference on e-Learning 2020 (pp. 170-174). IADIS Press. http:/ / www.iadisportal.org/digital-library/remote-teaching-for-deaf-pupilsduring-the-covid-19-emergency 
Bianchini, C. S., Borgia, F., \& De Marsico, M. (2019) SWift-A SignWriting editor to bridge between deaf world and e-learning. IEEE 12th International Conference on Advanced Learning Technologies 2012. (pp. 526-530). IEEE Press. https://doi.org/10.1109/ICALT.2012.235

Caupayan, J., \& Pogoy, A. (2021). Unheard stories of deaf students in online learning: A phenomenological study. SSRN. https://doi.org/10.2139/ssrn.3856136

Farhan, W., \& Razmak, J. (2020). A comparative study of an assistive e-learning interface among students with and without visual and hearing impairments. Disability and Rehabilitation: Assistive Technology, 1-11. https:// doi.org/10.1080/17483107.2020.1786733

Ibrahim, Z., Alias, N., \& Nordin, A. B. (2016). Needs analysis for graphic design learning module based on technology \& learning styles of deaf students. Cogent Education, 3(1), 1-14. https://doi.org/10.1080/2331186X.2016.1178364

Krishnan, I. A, Mello, G., Kok, S. A, Sabapathy, S., Munian, S., Ching, H. S, Kandasamy, P., Ramalingam, S., Baskaran, S., \& Kanan, V. (2020). Challenges faced by hearing impairment students during covid-19. Malaysian Journal of Social Sciences and Humanities, 5(8), 106-116. https://doi.org/10.47405/mjssh.v5i8.472

Mantzikos, C., \& Lappa, Ch. (2020). Difficulties and barriers in the education of deaf and hard of hearing individuals in the era of covid-19: The case of Greece-A viewpoint article. European Journal of Special Education Research, 6(3), 75-95. http://doi.org/10.46827/ejse.v6i3.3357

McClive, J., Mousley, K., Marchetti, C. E., Simkins, D., Blatto-Vallee, G., Jackson, J., \& Foster, S. (2020). supplemental online learning tools (SOLTs) to support deaf and hard of hearing students in introductory statistics courses. Journal of Science Education for Students with Disabilities, 23(1), 1-14.

https://doi.org/10.14448/jsesd.12.0009

McKeown, C., \& McKeown J. (2019). Accessibility in online courses: Understanding the deaf learner. Association for Educational Communications \& Technology, 63(5), 506513. https://doi.org/10.1007/s11528-019-00385-3

Merriam-Webster. (n.d.) Sign-language. In Merriam-Webster Dictionary. Merriam-Webster, Inc. https:// www.merriam-webster.com/dictionary/sign\%20language

Mingsiritham, K., \& Chanyawudhiwam, G. (2020). Experiment of the prototype of online learning resources on massive open online course (mooc) to develop life skills in using technology media for hearing impaired students. International Journal of Emerging Technologies in Learning. 15(3), 242-249. https://onlinejournals.org/index.php/i-jet/article/view/12059

Osman, M. E. (2020). Global impact of covid-19 on educationsystems: The emergency remote teaching at Sultan Qaboos University. Journal of Education for Teaching. 46(4), 463-471. https:// doi.org/10.1080/02607476.2020.1802583

Pappas, M., Demertzi, E., Papagerasimou, Y., Koukianakis, L., Kouremenos, D., Loukidis, L., \& Athanasios, D. (2018). E-learning for deaf adults from a user-centered

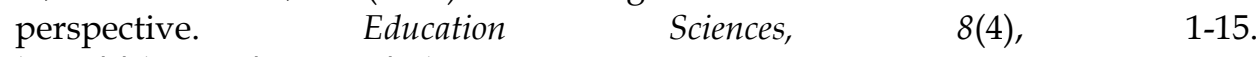
http://doi.org/10.3390/educsci8040206

Rasheed, R. A., Kamsin, A., \& Abdullah, N. A. (2020). Challenges in the online component of blended learning: A systematic review. Computers $\mathcal{E}$ Education, 144(2), 1-17. https://doi.org/10.1016/j.compedu.2019.103701

Salman, F. (2017, February 7). Fatima Al-Dhaen creates the message program (ASL PROMO) for the deaf and mute. Al Ayam Newpaper. https://www.alayam.com/

Samir, A., \& Tolba, M. (2015). A proposed standardization for arabic sign language benchmark database. The Egyptian Journal of Language Engineering, 2(1), 1-9. https://doi.org/10.21608/ejle.2015.60253 
Shohieb, S. (2019). A proposed gamified e-learning framework for teaching mathematics to arab deaf students. Ubiquitous Learning: An International Journal, 12(1), 55-70. https://doi.org/10.18848/1835-9795/CGP/v12i01/55-70

UNESCO (2020, March 6). Covid-19: 10 recommendations to plan distance learning solutions. https://en.unesco.org/news/covid-19-10-recommendations-plan-distancelearning-solutions

Weeden, E. M. (2018). Using web conferencing technology to foster inclusive course experiences for deaf and hard-of-hearing students [Doctoral dissertation, NSUWorks, College of Engineering and Computing]. https://nsuworks.nova.edu/gscis_etd/1032 